\title{
IMPLEMENTASI PENDIDIKAN KECAKAPAN HIDUP DI SLB B YAKUT PURWOKERTO MELALUI BUDIDAYA SAYURAN SECARA HIDROPONIK
}

\author{
Alpha Nadeira Mandamdari*, Eny Rokhiminarsi \\ Fakultas Pertanian, Universitas Jenderal Soedirman \\ *alpha.mandamdari@unsoed.ac.id
}

\begin{abstract}
Learning vegetable cultivation skills can be given to deaf children, because basically deaf children can be guided to take part in learning vegetable cultivation. To overcome this, the recommended vegetable cultivation skill to be implemented in SLB B Yakut Purwokerto is hydroponic vegetable cultivation. The target audience in this activity is the students of SLB B Yakut Purwokerto. The objectives of community service activities for students of SLB B Yakut Purwokerto are: (1) Increase the knowledge of SLB B Yakut Purwokerto students about hydroponic vegetable cultivation techniques, (b) Improve the skills of SLB B Yakut Purwokerto students in applying hydroponic vegetable cultivation techniques; and (c) Assisting training activities in hydroponic vegetable cultivation techniques at SLB B Yakut Purwokerto. The initial method used is a two-way discussion on the importance of cultivating vegetables using hydroponic techniques as an implementation of life skills education at SLB B Yakut Purwokerto. This discussion method is intended to make the target audience actively participate in the application of science and technology. Next, provide hydroponic vegetable cultivation training. The activity carried out at SLB B Yakut Purwokerto is the transfer of hydroponic vegetable cultivation technology with the selected commodity Pakcoy with the consideration that these commodities are easy to cultivate and the harvest period is relatively fast. PKM activities have increased the target audience's knowledge of the hydroponic vegetable cultivation system; and PKM activities have increased the skills of target audiences in hydroponic vegetable cultivation systems
\end{abstract}

Keywords: SLB B; hydroponic; vegetables; pakcoy

\begin{abstract}
Abstrak
Pembelajaran keterampilan budidaya sayuran dapat diberikan kepada anak tunarungu, dimana keterampilan budidaya sayuran yang direkomendasikan dilaksanakan di SLB B Yakut Purwokerto adalah budidaya sayuran secara hidroponik. Tujuan kegiatan pengabdian kepada masyarakat pada siswa SLB B Yakut Purwokerto adalah: (1) Meningkatkan pengetahuan siswa SLB B Yakut Purwokerto tentang teknik budidaya sayuran secara hidroponik, (b) Meningkatkan ketrampilan siswa SLB B Yakut Purwokerto dalam pengaplikasian teknik budidaya sayuran secara hidroponik; dan (c) Mendampingi kegiatan pelatihan teknik budidaya sayuran secara hidroponik di SLB B Yakut Purwokerto. Metode yang digunakan adalah berupa diskusi dua arah mengenai pentingnya budidaya sayuran hidroponik sebagai implementasi dari pendidikan kecakapan hidup di SLB B Yakut Purwokerto.Metode diskusi ini ditujukan agar khalayak sasaran turut berpartisipasi aktif dalam penerapan IPTEKS ini. Selanjutnya, memberikan pelatihan budidaya sayuran secara hidroponik serta dempot pada khalayak sasaran. Kegiatan yang dilakukan di SLB B Yakut Purwokerto adalah transfer teknologi budidaya sayuran secara hidroponik dengan komoditas yang dipilih adalah Pakcoy dengan pertimbangan komoditas tersebut mudah dibudidayakan dan masa panen yang relatif cepat. Kegiatan PKM telah meningkatkan pengetahuan khalayak sasaran terhadap sistem budidaya sayuran secara hidroponik; dan kegiatan PKM telah meningkatkan ketrampilan khalayak sasaran terhadap sistem budidaya sayuran secara hidroponik
\end{abstract}

Kata Kunci: SLB B; hidroponik; budidaya sayuran; pokcoy

\begin{tabular}{l|l|l} 
Submitted: yyyy-mm-dd & Revised: yyyy-mm-dd & Accepted: yyyy-mm-dd
\end{tabular}

\section{Pendahuluan}

Penyandang tunarungu sebagai warga masyarakat dituntut untuk mempunyai keterampilan untuk bekal hidupnya. Jenis keterampilan budidaya sayuran adalah salah satu jenis keterampilan yang cocok untuk penyandang tunarungu. Pembelajaran keterampilan budidaya sayuran dapat diberikan kepada anak tunarungu, karena pada dasarnya anak tunarungu dapat dibimbing untuk mengikuti pembelajaran budidaya sayuran. Hal tersebut dikarenakan mereka memiliki tingkat intelegensi rata-rata sama dengan anak pada umumnya, hanya keterbatasan pendengaran saja. 
Kondisi tunarungu yang ditekankan pada kemampuan visual dan motorik akan sangat sesuai untuk dapat membangun keahlian yang nantinya berguna sebagai bekal hidupnya.

Sementara ini mereka masih belajar menanam sayuran sederhana tanpa ada perlakukan khusus. Dengan bekal ini diharapkan mereka kelak dapat hidup mandiri atau tidak tergantung kepada orang lain. Pembekalan keterampilan ini menitik beratkan kepada keterampilan untuk menghasilkan suatu produk yang bermanfaat langsung bagi kehidupan. Dengan belajar budidaya sayuran dengan teknik yang tepat, diharapkan siswa SLB B Yakut Purwokerto dapat memperoleh pengalaman perseptual, pengalaman apresiatif, dan pengalaman kreatif. Keterampilan budidaya sayuran diharapkan dapat menjadi bekal agar mereka kelak dapat produktif secara ekonomi.

Berdasarkan kondisi dan situasi tersebut maka pemberian pelatihan dan demplot budidaya sayuran di SLB B Yakut Purwokerto diperlukan untuk meningkatkan pengetahuan dan ketrampilan siswa yang pada akhirnya nanti akan dapat meningkatkan keterampilan hidup bagi siswa setelah lulus sekolah. Selain itu, perlu dilakukan pendampingan mengenai proses budidaya sayuran degan teknik yang tepat.

\section{Metode}

Kegiatan Pengabdian dilaksanakan selama 6 bulan, dari bulan, dari Bulan Maret sampai oktober 2020. Khalayak sasaran adalah guru dan siswa SLB B Yakut Purwokerto. Pendekatan dan metode pengabdian yang dilakukan, yaitu: (1) Pembuatan demontrasi dan plot (demplot) hidroponik sayuran; (2) Melakukan kegiatan menanam sayuran dengan teknik budidaya yang tepat; (3) Mentransfer pengetahuan tentang budidaya sayuran

Evaluasi kegiatan dilakukan oleh Tim Pelaksana UNSOED terutama ditujukan kepada khalayak sasaran, meliputi aktivitas selama kegiatan pengabdian dan capaian pada saat kegiatan berakhir. Dalam kegiatan pengabdian kepada masyarakat ini, dilakukan beberapa tahapan evaluasi, yaitu: (1) Evaluasi pendahuluan dilakukan dengan membuat kuesioner sebelum kegiatan berlangsung (pre test) mengenai pengetahuan peserta tentang teknologi budidaya sayuran secara hidroponik, dan (2) Evaluasi setelah praktek dilakukan (post test) dengan cara praktek melakukan budidaya sayuran secara vertkultur.

Tolak ukur keberhasilan kegiatan diketahui dengan cara menilai atau membandingkan nilai pre test dengan post test sebelum kegiatan dan sesudah kegiatan pengabdian kepada masyarakat. Kriteria penilaian terdiri dari peningkatan pengetahuan dan keterampilan peserta tentang teknologi budidaya sayuran secara vertikultur. Untuk penilaian pengetahuan teknologi berupa kenaikan nilai, jika nilai antara post test dan pre test semakin besar maka hasil yang dicapai semakin baik. Penilaian keterampilan dengan metode praktek. Indikator keberhasilan yang diharapkan apabila $80 \%$ khalayak sasaran dapat menerapkan budidaya sayuran dengan teknik vertikultur dengan baik.

\section{Hasil dan Pembahasan}

Kegiatan pengabdian kepada masyarakat ini melibatkan berbagai pihak dimana kahalayak sasaran pada kegiatan ini adalah siswa SLB B Yakut Purwokerto. Manfaat yang diharapkan dari adanya kegiatan ini adalah memberikan keterampilan budidaya sayuran secara vertikultur kepada siswa SLB B Yakut Purwokerto sebagai bekal mereka kelak sudah tamat sekolah agar mereka dapat hidup mandiri.

Rencana awal pengabdian kepada masyarakat ini adalah melibatkan siswa SLB B Yakut Purwokerto pada setiap level untuk aktif mengikuti kegiatan budidaya sayuran yang dilakasanakan oleh Tim Pengabdi. Namun adanya pandemic COVID 19 yang mengharuskan kegiatanbelajar mengajar dilakukan secara daring (on-line) mengharuskan kegiatan ini sedikit berubah dari rencana semula. 
Langkah awal kegiatan Pengabdian kepada masyarakat adalah koordinasi yang dilakukan untuk menyamakan persepsi antar pihak yang terkait serta menyusun langkah strategis pelaksanaan program. Koordinasi ini bertujuan untuk memperoleh data mengenai kondisi pemanfaatan lahan pekarangan dan permasalahan yang dihadapi oleh khalayak sasaran, terlebih lagi adanya pandemic COVID 19. Koordinasi dilakukan pada 23 Juni 2020 dengan Kepala Sekolah SLB B Yakut Purwokerto, ibu Netty Lestari, S.Pd. Koordinasi membahas langkah-langkah yang dapat dilakukan dengan Tim Pengabdian Kepada Masyarakat terhadap transfer teknologi yang akan dilakukan pada kondisi pandemic COVID 19. Karena kegiatan belajar mengajar dilakukan secara daring, maka disepakai kegiatan ini tidak melibatkan siswa secara langsung sesuai dengan rencana semula. Jadi transfer teknologi dilakukan Tim Pengabdian Kepada Masyarakat kepada Guru terlebih dahulu baru setelah itu guru yang akan melakukan transfer teknologi kepada siswa. Pelatihan secara online kepada siswa dengan platform virtual meeting yang ada tidak memungkinkan karena kondisi siswa yang tidak memungkinkan untuk dilakukan virtual meeting. Dalam koordinasi ini juga disepakati bahwa siswa mendapatkan benih sayuran untuk ditanam masing-masing di rumah sebagai media pembelajaran mereka cara budidaya sayuran yang akan dimasukkan di dalam materi pembelajaran secara daring di sesuaikan dengan tingkatan/level kelas siswa. Selanjutnya guru yang akan memantau progress kegiatan siswa dalam budidaya sayuran di rumah. Sayuran yang disepakati adalah Bayam dan Kangkung dengan pertimbangan kedua jenis sayuran itu yang paling mudah untuk dibudiayakan bagi pemula dengan tingkat resiko kegagalan yang kecil.

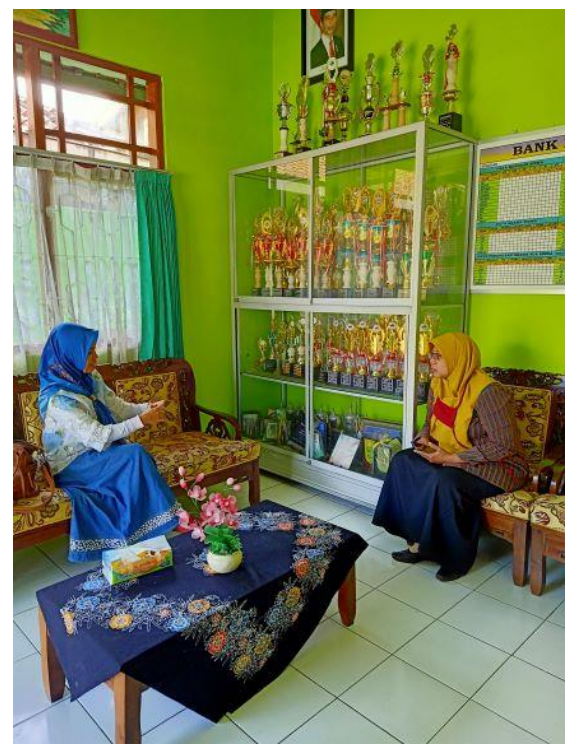

Gambar 1. Koordinasi dengan kepala sekolah SLB B Yakut Purwokerto terkait rencana kegiatan

Koordinasi ini juga menyepakati bahwa teknologi yang akan digunakan adalah hidroponik dengan pertimbangan mereka sudah pernah melakukan budidaya vertikultur walaupun masih sederhana. Sementara ini guru Sekolah ada yang pernah mengikuti pelatihan hidroponik secara online sehingga belum pernag secara langsung mempraktekkan hidroponik, baru sebatas teori yang telah di dapatkan selama pelatihan. Untuk itu Tim Pengabdian Kepada Masyarakat berdasarkan kesepakatan dengan Kepala sekolah akan membuat instalasi hidroponik di SLB B Yakut purwokerto yang diharapkan dapat bermanfaat bagi siswa untuk berlajar budidaya sayuran secara hidroponik. Pada tahap awal disepakati sayuran yang digunakan untuk budidaya secara hidroponik adalah Pakcoy karena paling mudah perawatan dengan tingkat resiko kegagalan yang rendah. 
BERNAS:

Jurnal Pengabdian Kepada Masyarakat

Instalasi hidroponik yang disepakati adalah hidropnik system NFT (Nutrient Film Technique). Hidroponik dengan sistem NFT merupakan suatu teknik ataupun metode penanaman yang akarnya ditumbuhkan pada lapisan larutan nutrisi dangkal. Larutan yang sudah berisi nutrisi tersebut sudah mendapat sirkulasi dengan baik, sehingga tanaman akan mendapat pasokan air, nutrisi sekaligus oksigen. Lapisan yang digunakan berjenis polyethylene dengan akar tanaman yang dibiarkan terendam di dalam air yang berisi nutrisi. Sementara, sirkulasi udaranya didapatkan dengan cara memompanya. Karena akar selalu tercukupi oleh pasokan oksigen, air dan juga nutrisi, maka tanaman yang berada di permukaan bisa tumbuh dengan cepat dan juga normal, selayaknya tanaman yang ditanam menggunakan media tanah.

Instalasi hidroponik NFT yang diaplikasikan di SLB B Yakut Purwokerto menggunakan media paralon. Media ini digunakan karena paling mudah didapat dan biaya perawatannya relative murah disamping itu umur ekonomisnya yang cukup lama (3 tahun) sehingga bisa digunakan secara terus menerus oleh Sekolah dan diharapkan ketika kegiatan belajar mengajar (KBM) kembali normal, instalasi ini masih dapat digunakan untuk media pembelajaran. Instalasi NFT ini dipasang pada tanggal 10 Agustus 2020 dan langsung ditaman benih pakcoy.
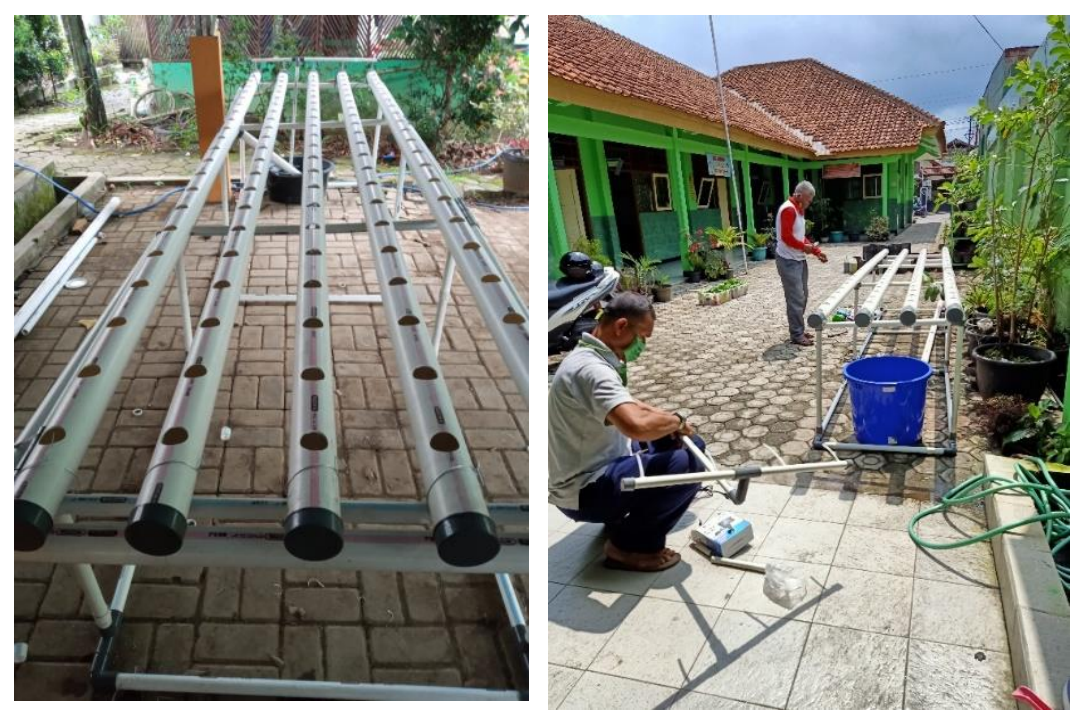

Gambar 2. Pemasangan Instalasi Hidroponik

NFT merupakan model budidaya hidroponik dengan menggunakan akar tanaman pada lapisan air yang dangkal. Air tersebut tersirkulasi dan mengandung nutrisi sesuai kebutuhan tanaman. Perakaran bisa berkembang di dalam larutan nutrisi. Karena disekeliling perakaran terdapat selapis larutan nutrisi, maka system ini dikenal dengan nama Nutrient film technique (NFT). Model NFT paling disukai karena perkembangan tanaman paling cepat, karena hanya ujung akar yang bersentuhan dengan larutan nutrisi sehingga oksigen juga lebih banyak diserap dari udara. Model NFT yang digunakan di SLB B Yakut Purwokerto adalah rak dengan jumlah pralon 4 dan ukuran model NFT nya adalah $4 \mathrm{~m} \times 1,2 \mathrm{~m}$. air mengalir secara gravitasi dari bagian tinggi ke rendah dengan ketinggian talang diukur dengan kemiringan $2-3 \%$. Untuk mengalirkan nutrisi menggunakan pompa, dimana nutrisi yang digunakan dimasukkan di dalam ember dengan debit air kurang lebih 1 liter/menit.

Bahan baku pupuk hidroponik yang digunakan berupa garam an organic atau garam kimia yang dibeli di took pertanian. nutrisi hidroponik yang digunakan menggunakan konsep formulasi 
AB mix. Yaitu kalsium pada group A dan tidak bertemu sulfat dan fosfat pada group B. Larutan A dan $B$ dibuat pada wadah yang berbeda sebelum dicampur menjadi satu. Untuk $A B$ mix, $5 \mathrm{ml}$ larutan A dicampur dengan $5 \mathrm{ml}$ larutan B yang kemudian dicampurkan ke dalam 1 liter air. Larutan ini sudah bisa digunakan untuk nutrisi hidroponik, dimana untuk 10 Liter larutan diperlukan $150 \mathrm{ml}$ Larutan $A B$ mix. Sebelum ditanam di dalam instalasi hidroponik, benih pakcoy disemai terlebih dahulu di net pot yang telah diisi rockwol. Baru setelah usia tanaman mencapai 15 hari, pakcoy dipindah ke instalasi hidroponik

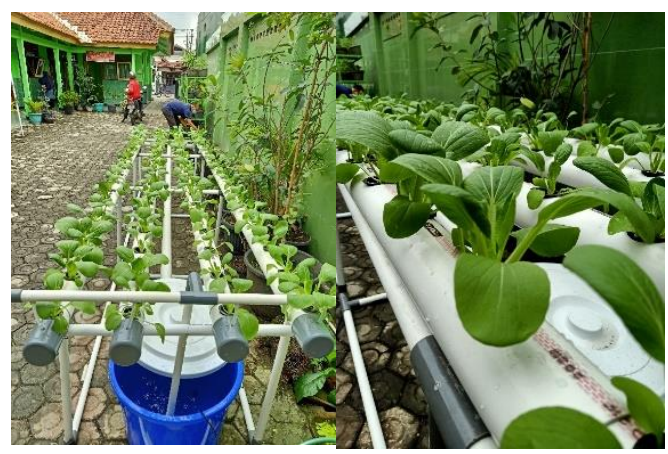

Gambar 3. Budidaya sayuran secara hidroponik

Agar siswa dapat belajar menanam sayuran secara mandiri, maka masing-masing siswa diberikan polybag serta benih sayuran berupa kangkung dan bayam beserta panduan cara menanam sayuran yang baik dan benar. Benih Kangkung dan bayam diberikan kepada siswa SLB B Yakut Purwokerto dengan dasar pertimbangan bahwa tanaman tersebut yang relatif paling mudah ditanam dan peluang berhasilnya relative besar dibandingkan tanaman sayuran lainnya. Setelah diberikan polybag dan benih, maka masing-masing siswa menaman sendiri di rumah dan didampingi oleh orang tuanya untuk siswa SD dan TK, sedangkan yang SMP dan SMA mereka bisa secara mandiri menanam dan memantau proses pertumbuhan tanamannya. Disamping polybag, siswa juga diberikan kartu kendali yang berfungsi untuk mencatat pertumbuhan tanaman mereka sampai siap panen.

Siswa menyambut antusias kegiatan ini karena mereka bisa belajar langsung menanam sayuran dan menikmati proses budidayanya seperti menyiram, melihat kondisi tanamannya apakah ada penyakit atau hama dan menyiangi bila ada gulma di sekitarnya. Dan yang tak kalah serunya adalah ketika mereka bisa memasak senri sayur bayam dan kangkung dari hasil panen mereka.

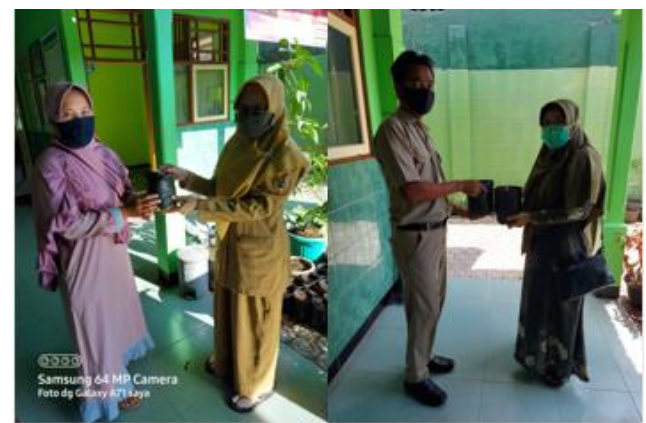

Gambar 4. Pemberian benih dan polybag secara simbolis dari guru ke wali murid SLB B Yakut Purwokerto 


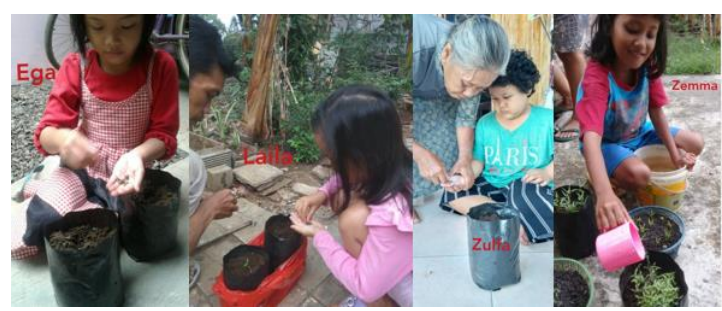

Gambar 5. Kegiatan bercocok tanam sayuran yang dilakukan di rumah masing-masing

Panen perdana budidaya sayuran secara hidroponik di SLB B Yakut Purwokerto dilakukan setelah tamanam berusia 45 hari. Panen dilakukan oleh Tim PKM Fakultas Pertanian UNSOED bersama dengan Kepala Sekolah dan seluruh Guru SLB B Yakut Purwokerto. Hasil panen perdana ini menunjukkan hasil yang memuaskan yang ditunjukkan dengan bentuk dan ukuran Pakcoy yang besar, hanya sedikit yang berukuran kecil maupun yang daunnya kuning. Secara berkala, guru yang ditugasi untuk memantau system hidroponik memastikan bahwa kondisi air dan tanaman dalam keadan baik dan mengecek apakah ada hama atau penyakit. Secara umum, panen perdana ini dikatakan berhasil karena hasilnya sesuai dengan harapan.

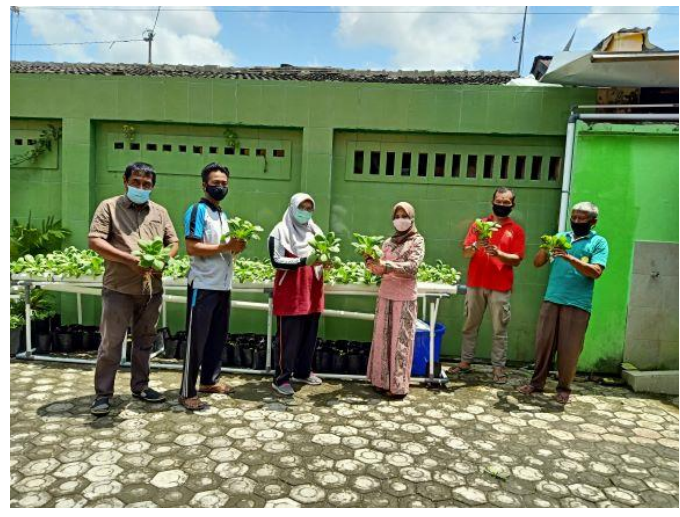

Gambar 7. Panen perdana pakcoy oleh Tim PKM Fakultas Pertanian UNSOED bersama Guru dan Kepala Sekolah SLB B Yakut Purwokerto

\section{Indikator Keberhasilan kegiatan}

Evaluasi kegiatan pengabdian dilakukan dengan cara membandingkan pengetahuan dan pemahaman warga sebelum dan sesudah kegiatan. Secara umum dapat menunjukkan bahwa terjadi penigkatan pengetahuan peserta mengenai budidaya sayuran secara hidroponik. Kegiatan ini dapat terlaksana dengan baik karena para guru yang bersemangat terhadap kegiatan ini dimulai dari koordinasi hingga tahap pemeliharaan sayuran. Mereka antusias ketika ada instalasi hidroponik dan siap memelihara serta menularkan teknologi hidroponik kepada siswa kelak bila sudah kembali normal

Faktor yang menjadi penghambat dalam pelaksanaan kegiatan ini adalah kurang efektifnya kegiatan ini dimana seharusnya khalayak sasarannya adalah siswa SLB B Yakut Purwokerto untuk membekali mereka dengan kecakapan hidup budidaya sayuran menjadi guru SLB B Yakut Purwokerto yang nantinya akan mentransfer teknologi ini kepada siswa-siswanya. Metode daring tidak dapat dilaknakan karena keterbatasan kemampuan siswa dalam menyerap teknologi secara daring. 


\section{Kesimpulan}

Dari hasil kegiatan yang telah dilakukan, maka ditarik kesimpulan sebagai berikut:

1. Kegiatan PKM telah meningkatkan pengetahuan khalayak sasaran terhadap sistem budidaya sayuran secara hidroponik

2. Kegiatan PKM telah meningkatkan ketrampilan khalayak sasaran terhadap sistem budidaya sayuran secara hidroponik

\section{Daftar Pustaka}

Damastuti, Anya P. Pertanian Sistem Vertikultur. Wacana No. 3 Juli - Agustus. 1996.

Fatmawati, et.al. 2018. Wiirausaha Pembuatan Kue Kering Untuk Meningkatkan Keterampilan Hidup Anak tunarungu. Jurnal Penelitian pendidikan Kebutuhan Khusus. Volume 6 No. II Tahun 2018.

Ishartiwi. 2012. Pembelajaran Keterampilan Untuk Pemberdayaan Kemandirian Anak Berkebutuhan Khusus. https://eprints.uny.ac.id/4219/. Diakses pada tanggal 1 November 2019

Kusmiati, A dan Umi, S. 2015. Peningkatan Pendapatan Keluarga Melalui Pemanfaatan Pekarangan Rumah Dengan Menggunakan Teknik Vertikultur. Inovasi dan Kewirausahaan. Vol 4. No 2 Mei 2015.

Lukman Liferdi. Teknolgi Budidaya Sayuran Secara Vertikultur.

Maharanto. 2000. Sayuran Pot di Negara 4 Musim. Trubus Edisis September No. 286. Tahun XXIV.

Nitisapto. 2000. Trend Baru: Bertanam Sayuran Dalam Pot. Trubus Edisi Agustus No. 285. Tahun XXIV. 2000

Rasapto, P. 2006. Budidaya Sayuran Dengan Vertikultur. Temu Teknis Nasional Tenaga Fungsional 2006. Pusat Penelitian dan Pengembangan Peternakan.

Tim Agromedia Pustaka. 2006. Memanfaatkan Rumah dan Pekarangaan Menanam Sayuran di Pekarangan Rumah. Agromedia Pustaka. Jakarta 